\title{
Assessment of knowledge and Attitude and Practice of Parents towards Epilepsy among Children in Abha City Asiri S. Hassan $\mathrm{A}^{\mathbf{1}}$, Alshehri S. Yahya $\mathbf{M}^{1}$, Alqutub A.Tariq $\mathrm{A}^{\mathbf{2}}$, Alqutub, Hussamaldin Tariq $\mathbf{A}^{2}$ \\ ${ }^{1}$ King Khalid University, ${ }^{2}$ King Abdulaziz University
}

\begin{abstract}
Background: Supporting information and high levels of awareness among parents could support the needs of the children and help in managing the outcomes of epilepsy.

Objectives: Studying the knowledge, attitude and practice (KAP) of Saudi parents in Abha City regarding epilepsy, Kingdom of Saudi Arabia (KSA).

Methods: It is a cross sectional study that was conducted during the period from February 2018 to May 2018 at Abha City, Saudi Arabia among 440 parents. The study tool was a questionnaire that consists of 20 questions regarding subject's demographics, knowledge, attitude and practice pattern.

Results: All the included parents rated the word epilepsy as common for them. Most of the subjects knows that epilepsy can be treated (84.3\%), 90.9\% knew that epilepsy is associated with hereditary and 52.5\% recognized that epilepsy can be caused by trauma or stroke but only $21.1 \%$ only knew that epilepsy could be treated by surgery. The knowledge of most of the respondents was adequate among $68.2 \%$. The attitude score was adequate among $76.4 \%$ of the parents. The practice score was adequate among $72.5 \%$ of the parents.

Conclusion: Most of Saudi parents in Abha showed adequate awareness about epilepsy among children which showed adequate attitude and practice pattern. This is suggestive to increasing the chances of management of the disease and decreasing the risk factors and complications of misconceptions.
\end{abstract}

Keywords: Knowledge, attitude, practice, Epilepsy, parents Abha city, children, 2018.

\section{INTRODUCTION}

Epilepsy is a neurological condition with common repeated seizures. In developing countries, the prevalence of epilepsy rated from 0.004 to $0.008 \%$ children suffered from epilepsy ${ }^{(\mathbf{1}, \mathbf{2})}$.

The prevalence of epilepsy in Kingdom of Saudi Arabia was about 7 cases out of 1000 children $^{(2,3)}$. According to the WHO, about 50 million subjects suffer from epilepsy around the world and most of them (85\%) are from developing countries as about 4.7 million epilepsy cases are located in the Eastern Mediterranean Region ${ }^{(4)}$.

During the last decades, the worldwide awareness regarded epilepsy and its effects on child and caregivers ${ }^{(5,6)}$. Also, the attitudes of parents are suggestively associated with the epilepsy complications among children including the duration and intensity of seizures as the fears from parent's attitudes could affect the behavioral and psychological outcomes of children ${ }^{(7)}$. Supporting information and high levels of awareness among parents could support the needs of the children and help in managing the outcomes of epilepsy ${ }^{(\mathbf{8 , 9})}$.

However, the level of awareness and perceptions of population in KSA still requires improvement and the studies regarding the parental knowledge are limited ${ }^{(6,10)}$.

To understand the parental knowledge regarding epilepsy, more surveys and international care delivery should be done that could influence the knowledge of the entire family.

\section{AIM OF THE STUDY}

The present study aimed at studying the knowledge, attitude and practice (KAP) of Saudi parents in Abha City regarding epilepsy.

\section{METHODS}

Study design:

It is a cross sectional study that was conducted during the period from February 2018 to May 2018 at Abha City, Saudi Arabia.

Study population and sample size:

The included sample size was designed established on the equation $(\mathrm{n}=\mathrm{Z} 2 \mathrm{PQ} / \mathrm{d} 2)$ taking the total size $720022^{\mathbf{( 1 1 )}}$ with a margin error $(5 \%)$ and a confidence level (95\%). The sample size was 370 and additional $20 \%$ were added then the total sample obtained was $440^{(12)}$. The subjects were randomly chosen using multiple stratified random sampling technique. The participants were interviewed in 4 different shopping malls in different parts of Abha City. A consent was given by the participants enrolled in the study.

Study tools:

The study tools included a questionnaire and an interview with the respondents, the questionnaire consisted of 20 questions that were translated into Arabic after reviewing the available studies found on medical database. The questionnaire included questions about subject's demographics, knowledge, attitude and practice pattern.

\section{Statistical analysis:}

The statistical analysis was done using the Statistical Package for Social Sciences version 20 (SPSS Inc., Chicago, IL, USA). 


\section{RESULTS}

\section{Characteristics of the studied subjects:}

The characteristics of the included parents are shown in Table 1. The age of participants was 3040 years old among $40.5 \%$ of the parents and $41-50$ years old among $28.6 \%$ and was 51-60 years old among $30.9 \%$. The majority of respondents were males $(52 \%)$ and the rest (48\%) were females. Most of the subjects had college degree $(73.6 \%)$ and $26.4 \%$ were at secondary or primary school. The most prominent source of knowledge was internet among (59.8\%) (Table. 1).

Table (1): Demographic of included parents(440)

\begin{tabular}{|l|c|c|}
\hline & No. & Percentage (\%) \\
\hline Age & & \\
$30-40$ & 178 & 40.5 \\
$41-50$ & 126 & 28.6 \\
$51-60$ & 136 & 30.9 \\
\hline Gender & & \\
Female & 211 & $48 \%$ \\
Male & 229 & $52 \%$ \\
\hline Educational Level & & \\
Collage & 324 & $73.6 \%$ \\
Secondary or primary School & 116 & $26.4 \%$ \\
\hline Source of knowledge & & \\
Relatives and friends & 86 & $19.5 \%$ \\
Internet & 263 & $59.8 \%$ \\
Media & 39 & 8.9 \\
Health professional & 52 & $11.8 \%$ \\
\hline
\end{tabular}

\section{Level of knowledge of included subjects:}

All the included parents rated the word epilepsy as common for them. Most of the subjects knows that epilepsy can be treated (84.3\%), 90.9\% knew that epilepsy is associated with hereditary and all of them correctly knew that epilepsy is not a contagious disease as well as $52.5 \%$ recognized that epilepsy can be caused by trauma or stroke. On the other hand, only $37.5 \%$ had good knowledge about not considering epilepsy as mental or psychiatric disease and only $21.1 \%$ only knew that epilepsy could be treated by surgery (Table. 2).

Table (2): Awareness regarding the epilepsy (440):

\begin{tabular}{|l|c|c|}
\hline & Correct & Incorrect \\
\hline $\begin{array}{l}\text { Is the word epilepsy common to } \\
\text { you? }\end{array}$ & $440(100 \%)$ & $0(0 \%)$ \\
\hline Epilepsy can be treated & $371(84.3 \%)$ & $69(15.7 \%)$ \\
\hline $\begin{array}{l}\text { Epilepsy is not a mental or } \\
\text { psychogenic condition }\end{array}$ & $165(37.5 \%)$ & $275(62.5 \%)$ \\
\hline Epilepsy is a hereditary disease & $400(90.9 \%)$ & $40(9.1 \%)$ \\
\hline Epilepsy is not a contagious disease & $440(100 \%)$ & $0(0 \%)$ \\
\hline $\begin{array}{l}\text { Epilepsy could be caused by } \\
\text { trauma or stroke }\end{array}$ & $209(47.5 \%)$ & $231(52.5 \%)$ \\
\hline $\begin{array}{l}\text { Epilepsy could be treated with } \\
\text { surgery }\end{array}$ & $93(21.1 \%)$ & $347(78.9 \%)$ \\
\hline
\end{tabular}

Level of knowledge among respondents:

The knowledge of most of the respondents was adequate among $68.2 \%$ (Table. 3 ).

Table (3): Respondents' knowledge of epilepsy among children.

\begin{tabular}{|l|c|c|}
\hline \multicolumn{1}{|c|}{ Knowledge level } & Frequency & Percent (\%) \\
\hline Good & 300 & 68.2 \\
\hline Poor & 140 & 31.8 \\
\hline Total & 440 & 100.0 \\
\hline
\end{tabular}

Evaluating the subject's attitude:

The attitude of included parents is presented in table 4. Most of the subjects showed positive attitude toward the ability of epileptic child to live and learn equally in the society (93.6\%). Also, $68.6 \%$ agree that epilepsy doesn't impact the daily activities, $57.5 \%$ showed that the intelligence of epileptic person is not affected and all of them has positive attitude toward not considering the epileptic person as an obstacle on the society.

Table (4): Attitude of parents toward epilepsy ( $n=440)$.

\begin{tabular}{|l|c|c|}
\hline & No. & Percentage (\%) \\
\hline $\begin{array}{l}\text { Epileptic child can live and learn like } \\
\text { others in the society }\end{array}$ & & \\
$\quad$ Agree & 412 & 93.6 \\
Disagree & 28 & 6.4 \\
\hline $\begin{array}{l}\text { Epilepsy doesn't impact the person's } \\
\text { daily activities }\end{array}$ & & \\
$\quad$ Yes & 302 & 68.6 \\
$\quad$ No & 138 & 31.3 \\
\hline $\begin{array}{l}\text { Epilepsy patients should be kept } \\
\text { away from other persons }\end{array}$ & & \\
$\quad$ Yes & 12 & 2.7 \\
$\quad$ No & 428 & 97.3 \\
\hline $\begin{array}{l}\text { The intelligence of epileptic persons is } \\
\text { lower than normal persons }\end{array}$ & & \\
$\quad$ Agree & 187 & 42.5 \\
$\quad$ Disagree & 253 & 57.5 \\
\hline Epileptic persons is obstacle on the & & \\
society and health authorities & & \\
Agree & 0 & 0 \\
Disagree & 440 & 100 \\
\hline
\end{tabular}

Attitude score among respondents:

The attitude score was adequate among $76.4 \%$ of parents (Table. 5 ).

Table (5): Attitude score among respondents:

\begin{tabular}{|l|c|c|}
\hline \multicolumn{1}{|c|}{ KAP level } & Frequency & Percent (\%) \\
\hline Good & 336 & 76.4 \\
\hline Poor & 104 & 23.6 \\
\hline Total & 440 & 100.0 \\
\hline
\end{tabular}

Practice pattern of included subjects:

More than half of the participants would call ambulance for convulsing child (51.6\%), most of them would follow up with a doctor $(82.7 \%)$ and $84.8 \%$ will act normally with relatives or epileptic persons (Table. 6). 
Table (6): Practice of parents toward epilepsy $(n=440)$.

\begin{tabular}{|l|c|c|}
\hline & No. & $\begin{array}{c}\text { Percentage } \\
(\%)\end{array}$ \\
\hline $\begin{array}{l}\text { What is your action after seeing a } \\
\text { child suffering from convulsions }\end{array}$ & & \\
$\quad$ I call ambulance & 227 & 51.6 \\
$\quad$ I give him the first aid & 59 & 13.4 \\
$\quad$ I don't know what to do & 154 & 35 \\
\hline $\begin{array}{l}\text { What will you do if you suffer from } \\
\text { epilepsy }\end{array}$ & 44 & \\
$\quad$ Use herbal medicine & 364 & 82.7 \\
$\quad$ Follow up with a doctor & 32 & 7.3 \\
$\quad$ No need for treatment & & \\
\hline What is your reaction toward & & \\
epileptic patient & 67 & 15.2 \\
$\quad$ I will leave him & 373 & 84.8 \\
\hline I will act normally with him &
\end{tabular}

Practice score among respondents:

The practice score was adequate among $72.5 \%$ of parents as presented in Table. 7 .

Table (7): Respondents' practice score of epilepsy among children.

\begin{tabular}{|l|c|c|}
\hline \multicolumn{1}{|c|}{ KAP level } & Frequency & Percent (\%) \\
\hline Good & 319 & 72.5 \\
\hline Poor & 121 & 27.5 \\
\hline Total & 440 & 100.0 \\
\hline
\end{tabular}

\section{DISCUSSION}

This isn't the first study conducted in KSA to evaluate the KAP of Saudi parents toward children epilepsy but it is the first in Abha city. The results were surprising and very different from most of the conducted in Arab countries as most of the subjects had good KAP toward epilepsy among children.

The source of knowledge among most of the subjects was internet showing its importance among populations recently and this was shown in a study conducted by Diaz et al. ${ }^{\left({ }^{(3)}\right.}$. However, another study showed that the preferred source of knowledge among parents is physician or nurse as they are the source of most trustful information ${ }^{(14)}$. But another study showed that neither physician nor nurse have free time to give parents the full information they need ${ }^{(15)}$.

The high KAP score in this study showed that it can determine and overcome the obstacles suffered by epileptic patients. However, a study conducted in developing countries showed that the knowledge and beliefs of parents were wrong among most of them ${ }^{(16)}$. Also, many studies conducted in KSA showed the same results as the level of knowledge was significantly poor and was associated with the level of education ${ }^{(1,17-19)}$.

On the other hand consistent study conducted in Aseer region showed that the majority of Saudi population already heard the word epilepsy or searched for it on internet ${ }^{(18)}$ which was presented among other studies from different regions ${ }^{(20-22)}$.

This study showed that most of the subjects knows that epilepsy can be treated but the knowledge about surgery was inadequate to what was represented in other studies ${ }^{(23)}$.

The attitude of most of the parents was proper comparable to a study conducted in Italy showing good attitude toward dealing with epileptic children in good manner ${ }^{(24)}$ and among Saudi families in Riyadh city ${ }^{(20)}$. Contrast study showed that the Saudi population in Jeddah city had negative attitudes toward dealing normally with epileptic child ${ }^{(23)}$.

The practice pattern was adequate among most of the subjects regarding helping epileptic subjects and this was consistent with other studies in KSA ${ }^{(25)}$.

\section{CONCLUSION}

Most of Saudi parents in Abha showed adequate awareness about epilepsy among children which showed adequate attitude and practice pattern. This is suggestive to increase the chances of management of the disease and decrease the risk factors and complications of misconceptions.

\section{REFERENCES}

1. Almutairi AM, Ansari T, Sami W et al. (2016): Public knowledge and attitudes toward epilepsy in Majmaah. J Neurosci Rural Pract., 7:499-503.

2. Al Rajeh S, Awada A, Bademosi O et al. (2001): The prevalence of epilepsy and other seizure disorders in an Arab population: a community-based study. Seizure, 10:410-414.

3. Benamer HT, Grosset DG (2009): A systematic review of the epidemiology of epilepsy in Arab countries. Epilepsia, 50:2301-2304.

4. WHO (2010): World Health Organization. Epilepsy in the WHO Eastern Mediterranean Region: bridging the gap. Cairo (EG): World Health Organization, Regional Office for the Eastern Mediterranean Region. Available from: http:// www. who. int/ mental_ health/ neurology/ epilepsy/emro_report.pdf?ua $=1$. 
5. Hagemann A, Pfafflin M, Nussbeck FW et al. (2016): The efficacy of an educational program for parents of children with epilepsy (FAMOSES): Results of a controlled multicenter evaluation study. Epilepsy and behavior,64:143-151.

6. Asiri NA, Bin Joubah MA, Khan SM et al. (2015): Maternal knowledge of acute seizures. Neurosciences (Riyadh, Saudi Arabia), 20:346-349.

7. Austin JK, Haber LC, Dunn DW et al. (2015): Children with new onset seizures: A prospective study of parent variables, child behavior problems, and seizure occurrence. Epilepsy and behavior, 53:73-77.

8. Duffy LV (2011): Parental coping and childhood epilepsy: the need for future research. J Neurosci Nurs., 43:29-35.

9. Carmassi C, Corsi M, Bertelloni CA et al. (2018): Mothers and fathers of children with epilepsy: gender differences in post-traumatic stress symptoms and correlations with mood spectrum symptoms. Neuropsychiatric disease and treatment, 14:1371-1379.

10. Alaqeel A and Sabbagh AJ (2013): Epilepsy; what do Saudi's living in Riyadh know? Seizure, 22:205-209.

11. GASKSA (2017): General authority for statistic kingdom of Saudi Arabia https:// www.stats.gov.sa/sites/default/files/ar-taboukpulation- by-gender-govnernorate-nationality_1.pdf.

12. Charan J and Biswas T (2013): How to calculate sample size for different study designs in medical research? Indian J Psychol Med., 35:121-126.

13. Diaz JA, Griffith RA, Ng JJ et al. (2002): Patients' use of the Internet for medical information. Journal of general internal medicine, 17:180-185.

14. Kendall S, Thompson D and Couldridge $L$ (2004): The information needs of carers of adults diagnosed with epilepsy. Seizure, 13:499-508.

15. Coulter DL and Koester BS (1985): Information needs of parents of children with epilepsy. Journal of developmental and behavioral pediatrics, 6:334-338.

16. Sidig A, Ibrahim G, Hussein A et al. (2009): A study of knowledge, attitude, practice towards epilepsy among relative of epileptic patients in Khartoum State. Sudanese journal of public health, 4:393-398.
17. Neyaz HA, Aboauf HA, Alhejaili ME et al. (2017): Knowledge and attitudes towards epilepsy in Saudi families. Journal of Taibah University Medical Sciences, 12:89-95.

18. Alhazzani AA, Alqahtani AM, Abouelyazid A et al. (2016): Public awareness, knowledge, and attitudes toward epilepsy in the Aseer region, Saudi Arabia - A community-based crosssectional study. Epilepsy and behavior, 63:63-66.

19. Alqahtani JM (2015): Knowledge and practice of schoolteachers towards students with epilepsy in Khamis Mushate, Southern Saudi Arabia. Journal of Family and Community Medicine, 22:163-168.

20. Alaqeel A and Sabbagh AJ (2013): Epilepsy; what do Saudi's living in Riyadh know? Seizure, 22:205-209.

21. Daoud A, Al-Safi S, Otoom S et al. (2007): Public knowledge and attitudes towards epilepsy in Jordan. Seizure, 16:521-526.

22. Njamnshi AK, Bissek AC, Yepnjio FN et al. (2010): A community survey of knowledge, perceptions, and practice with respect to epilepsy among traditional healers in the Batibo Health District, Cameroon. Epilepsy \& behavior, 17:95-102.

23. Zainy LE, Atteyah DM, Aldisi WM et al. (2013): Parents` knowledge and attitudes toward children with epilepsy. Neurosciences (Riyadh, Saudi Arabia), 18:345-348.

24. Savarese G, Carpinelli L, D'Elia D et al. (2015): Teachers of various school grades and representations of epilepsy: problems, relational aspects and perspectives of life quality. Ital J Pediatr., 41:70.

25. Obeid T, Abulaban A, Al-Ghatani F et al. (2012): Possession by 'Jinn' as a cause of epilepsy (Saraa): a study from Saudi Arabia. Seizure, 21:245-249. 